\title{
"I Feel Quite Hopeful that My Future Is Still Going to be Okay": Educational Aspirations During COVID-19
}

\author{
Blaise Y. O’Malley ${ }^{1,2}$, Colleen Loomis ${ }^{2,3}$, Christina Dimakos ${ }^{4}$, Sylvie L. Lamont ${ }^{2}$, Gurmakh Singh $^{2}$, Janette \\ Pelletier ${ }^{4}$, Brian D. Christens ${ }^{5}$, Carrie Wright ${ }^{2,3,6} \&$ Ray DeV Peters ${ }^{7}$ \\ ${ }^{1}$ The Dartmouth Institute for Health Policy \& Clinical Practice, Dartmouth College, Hanover, United States \\ ${ }^{2}$ Wilfrid Laurier University, Waterloo, Canada \\ ${ }^{3}$ Balsillie School of International Affairs, Waterloo, Canada \\ ${ }^{4}$ Ontario Institute for Studies in Education, University of Toronto, Toronto, Canada \\ ${ }^{5}$ Vanderbilt University, Nashville, United States \\ ${ }^{6}$ Applied Research, Innovation, \& Evaluation Services, Waterloo, Canada \\ ${ }^{7}$ Queen's University, Kingston, Canada \\ Correspondence: Blaise Y. O’Malley, Wilfrid Laurier University, Waterloo, Ontario, N2L 3C5, Canada. E-mail: \\ bomalley@wlu.ca
}

Received: May 3, 2021 Accepted: June 11, 2021 Online Published: June 16, 2021

doi:10.5539/jel.v10n4p78 URL: https://doi.org/10.5539/jel.v10n4p78

\begin{abstract}
The COVID-19 pandemic has radically altered how we learn, work, and live. This qualitative research aimed to study the effects of the COVID-19 pandemic on the educational and occupational aspirations of young Canadian adults. All close to 29 years of age, sixteen participants took part in one-on-one semi-structured interviews conducted through Zoom. Questions probed participants' hopes, dreams, and perceived obstacles regarding school and work. Coding was completed using the research software Dedoose. Thematic content analysis was performed using both deductive and inductive approaches. Three themes emerged: the benefits and drawbacks of working and learning from home; financial changes and concerns; and hope and optimism despite challenges posed by the pandemic. Working and learning from home were discussed by $88 \%$ of participants, making it the most prominent theme. Participants generally agreed that working and learning from home had many benefits, but some expressed concern about the quality of online education. In addition, the pandemic caused financial hardship for a few participants, forcing them to delay educational or occupational plans. However, the majority (75\%) expressed positivity and hope for the future. Overall, although the timeline of some participants' educational or occupational plans changed, their aspirations largely remained the same.
\end{abstract}

Keywords: COVID-19, pandemic, educational aspirations, occupational aspirations

\section{Introduction}

The COVID-19 pandemic has dramatically altered several facets of our lives. In particular, work and schooling have been significantly impacted in Canada and around the world. Within the first month of the pandemic alone, Canada's national unemployment rate increased from 7.8\% to $13.0 \%$ (Labour Market Information Directorate, 2020). For those fortunate enough to keep their jobs, many had to start working from home, and students of all ages were forced to adapt to virtual learning. This shift has drastically changed the landscape of education and work, with many speculating that such changes will remain long after the pandemic is over (García-Morales et al., 2021).

Many people identify the late twenties and early thirties as a period of time formative to their education and career (Duta et al., 2021). Individuals in this age range may consider finishing a degree program, switching jobs, or pursuing additional post-secondary education. In Canada, the number of 25-34-year-old students enrolled in higher education has increased over the past several years; between the 2010-2011 and 2018-2019 academic years, the number of post-secondary students in this age group increased by approximately $10.3 \%$ (Statistics Canada, 2020). Although more recent enrollment statistics are not yet available, the pandemic raises questions about how young adults will be impacted, particularly in relation to educational and career goals.

The impact that the pandemic could have on academic and professional goals is important to consider, as 
educational and occupational aspirations and goals have been associated with academic achievement and post-secondary school enrollment (Agger et al., 2018; Ahuja, 2016). For the purpose of this study, we define educational aspirations as the level and type of education one hopes to achieve and occupational aspirations as the career one hopes to achieve (Boxer et al., 2011). Research shows that these aspirations are influenced by numerous factors, including engagement in school, socioeconomic status, and mental health (Neal \& Yelland, 2014; Puzić et al., 2019; Rothon et al., 2011). In a study on emotional engagement and educational aspirations of London high school students, Gutman and Schoon (2018) found that adolescents who were more engaged in school reported higher aspirations and less uncertainty regarding their aspirations. Other studies have shown that students who value education and have a positive attitude towards school are more likely to have high aspirations (Geckova et al., 2010; Scandone, 2018; Wang \& Eccles, 2012). Although socioeconomic status seems to have some effect on educational aspirations, findings on this relationship have been less consistent. Some research has shown high aspirations across a socioeconomically diverse sample (e.g., Frostick et al., 2016) and in refugee youth (e.g., Shakya et al., 2012), while other studies have found a positive association between the two variables (Puzić et al., 2019; Stockfelt, 2016). There also appears to be an association between educational aspirations and health, including mental health and health behaviours. In a study of Canadian high school students, Williams et al. (2020) found that cannabis use was associated with lower aspirations and expectations of attaining a bachelor's or master's degree, and tobacco users had lower academic aspirations and expectations than those who had never used tobacco. Another study, which explored the educational aspirations of adolescents in the United Kingdom, found that psychological distress was associated with lower educational aspirations while self-esteem was associated with a desire to remain in post-compulsory education (Rothon et al., 2011).

Much of the research on educational and occupational aspirations has focused on adolescents and the high school experience. There is a paucity of research on the continued educational hopes and dreams among young adults. As reviewed above, given that the pandemic has had an impact on several factors related to such aspirations - student engagement with school (Gutman \& Schoon, 2018), socioeconomic status (Frostick et al., 2016), health (Williams et al., 2020) - it seems reasonable to assume that the pandemic has also impacted educational and occupational aspirations more directly. The current qualitative study sought to explore the impact of the coronavirus pandemic on young adults in Canada by posing the question, "How has the COVID-19 pandemic affected the educational (and occupational) aspirations and plans of Canadian young adults?"

\section{Method}

The current sample $(N=16)$ was drawn from a larger longitudinal study about growing up in Ontario, Canada. Participants had previously consented to be contacted for future research. These former research participants were invited to take part in a study about educational aspirations with a $\$ 25$ remuneration. The average age was 29 , and there were 10 women and 6 men. The education level of the sample includes five individuals with a master's degree, two who had completed post-secondary, five who had some post-secondary, two individuals with some secondary, and two with other types of education or training. All participants were employed, $56 \%$ full-time and $44 \%$ part-time, with two looking for work. The average monthly household income was $\$ 4075$, ranging from $\$ 990$ to $\$ 10,000$ (Canadian dollars); one person was receiving financial assistance from the government. In terms of living situation, eight participants were living with a partner, three alone, two with parents, two with friends, and one who reported "other."

\subsection{Interview Guide}

The study used a semi-structured interview guide with open- and closed-ended questions (see Table 1) and included specific questions related to both educational/occupational aspirations and the impact of the COVID-19 pandemic. Closed-ended questions (2-5) were followed up by probing for further elaboration. Knowing that education levels varied in the sample, the questions about hopes and dreams intentionally probed for education and work. After verbal assent to participate in the study was received from participants, the interview opened with questions about hopes and dreams, people who influenced those dreams, as well as the challenges and facilitators that impacted these dreams over four time periods: (1) during high school (2) upon finishing high school, (3) most recently pre-pandemic, and (4) since the coronavirus pandemic was declared. This study focused on analyses of the pandemic-specific interview questions.

\subsection{Recruitment and Data Management}

A total of 357 participants had provided previous consent to be contacted for future research studies. Using stratified random sampling by education level (5 levels) and gender (2 levels), with three individuals in each group, the target sample was 60 . Using sampling with replacement, when a potential participant did not respond, we drew another individual from the larger sample. In total, we sent invitations to participate to 95 individuals: 40 did not 
respond, 8 declined, and 47 were interviewed. After receiving approval from an institutional research ethics board, the initial invitation to participate was sent via email (Day 1). If no response was received, the individual's alternative contact method (most commonly a phone number) was used on Day 4. Reminder emails were sent on Days 8 and 16, and the alternate contact method was used again on Day 12. When a particular stratification group was filled, recruitment for that group stopped. Of the 47 participants who agreed to be interviewed, Of the 47 who completed interviews, 16 spoke meaningfully about their experiences with COVID-19. The video-conferencing platform Zoom was used to conduct the interviews. Interviews were recorded after receiving the participant's verbal consent and stored on a secure database for researcher access. These interviews took place from August 6 to October 2, 2020. Interview audio files were then uploaded to an online transcription service (both Sonix.ai and Otter.ai were used), and some corrections were made manually by research assistants. Video files were deleted.

\subsection{Coding and Thematic Analysis}

Coding was conducted using Dedoose, a software program used for qualitative and mixed methods research. Coding the transcripts was an iterative process, with some codes being added after the interview process had begun: 18 were directly related to the COVID-19 pandemic. Five randomly selected interview transcripts were coded by four researchers to assess inter-rater agreement; once this was established, the remaining transcripts were coded by one research assistant. After coding was complete, the same research assistants conducted an audit trail, and the principal investigator reviewed the codes and memos.

Next, thematic analysis was conducted by reading each excerpt with a COVID-19 related code. Once themes were determined from this assessment, findings were discussed. Finally, to further ensure trustworthiness and convergence, other researchers reviewed the themes and related interview excerpts and met to discuss the findings.

Table 1. Interview guide questions related to the impact of the COVID-19 pandemic

1. Tell me about how the coronavirus has changed your educational (or occupational) hopes.

2. Before the virus, did you define yourself as hopeful or hopeless about pursuing your dreams? What changed/remained the same for you?

3. Before the virus, you mentioned you were interested in __. Are you still interested in pursuing that area of study, or have you changed your focus?

4. With the current health concerns, have you considered switching to public health, medicine, nursing, or some other healthcare provider pursuit?

5. Health is not the only aspect of society impacted by the virus. Have you considered shifting your focus because the pandemic makes you think differently now about future employment?

6. Resources: How have technical factors influenced your educational plans?

\section{Results}

The sixteen participants provided in-depth comments on COVID-19 and its impact on their educational and occupational aspirations and plans. Three central themes emerged from the data, each with 2 to 3 sub-themes.

\subsection{Benefits and Drawbacks of Working and Learning from Home}

The most prominent theme throughout the interviews was working and learning from home $(n=14,88 \%)$. This theme was characterized by issues of access, preferred learning styles, and balancing work and family with participation in formal education. No demographic differences were observed.

\subsubsection{Distance Learning Improves Access to Education}

Six of the 16 participants (38\%) spoke about virtual or distance learning as a result of the pandemic. Most discussed how the increase in distance learning promotes greater access to education and greater flexibility in their lives. In particular, multiple participants mentioned that learning from home would allow them to balance a job with schooling.

"I would say it would actually make it easier for me to if I wanted to go back to school...So because, you know, education and courses are going to be online, I feel like even if I'm home, I can access that. I don't have to go in person. Maybe I can manage like a part-time job and schooling at the same time. So I think it's actually affected me in more of a positive way." (INT8)

"I guess what I'm saying is that because there's so much distance learning, I kind of figured that there's going to be a program out there that I'd be able to take, that I'd be able to do from home or through online with some in-class requirements, wherever that might be. But that's the only way that I could see myself doing that, 
with like, with my family commitments and work commitments and all that." (INT2)

"I think it would help me to go back to school if everything was online." (INT4)

"If it was something that I was really interested in, it was able to, like, hold my attention... I would definitely do it, especially if I could just do it online.” (INT11)

\subsubsection{For Many, in-Person Learning Is Preferred}

Although many participants expressed appreciation for the accessibility provided by distance learning, some felt that in-person learning was superior. They felt that the learning experiences were different and that in-person interactions were essential to learning.

"I don't like learning online. I prefer in-person. I'm a person, like, I need someone beside me when they teach me or else I'm like, No, I need help." (INT16)

"I know I definitely don't want to do distance learning...I don't have the same focus...so it's very, very difficult to get anything done. And I know that it wouldn't be very beneficial to my learning." (INT12)

\subsubsection{Working from Home Allows for Greater Flexibility}

Many participants highlighted the benefits of working from home, which they recognized were made possible due to the pandemic. A virtual work arrangement allows for greater flexibility and is more conducive to having a family.

“I don't have to leave my home. I can do counselling in my own home while my baby's taking a nap. And it's just like seeing that would never have happened if the pandemic didn't happen...for me, it's been quite positive." (INT13)

"I'm lucky to work from home now. And that's all I've wanted. For the longest time...I don't have to commute all the way downtown in a 40-minute bus ride every morning and night and drop off my daughter and not see her from 6:30 in the morning to 5:00 at night...it gave me the opportunity to start a job from home, a job that I'm enjoying and that I'm fully dedicating myself to." (INT3)

"The upside of the pandemic is that, that might be, like given that it's just a work from home now, I might just go to a different country and work from home because the office is not open at once. So that's the upside. And if it stays long enough, then I can maybe continue doing that for a little bit." (INT5)

\subsection{Financial Changes and Concerns}

Over a third of participants (38\%) discussed the effect of the pandemic on their job security and finances. Although most of these individuals expressed concern about their employment or financial situation, one participant stated that they benefited from being laid off.

\subsubsection{The Pandemic Increased Feelings of Job Insecurity}

Some participants who were currently working expressed newfound uncertainty or concern related to their job security.

“...knowing how many people have lost their jobs and how much of the job market has changed so quickly, is like really also terrifying." (INT1)

Another participant questioned whether to return to school to pursue a profession that would always be in demand.

"I was kind of concerned about job security. I know a lot of organizations were shutting down, a lot of programs were closing down. So I thought maybe I should try to pursue something where they're like, that is kind of needed everywhere. So I was looking at different options and I even thought of maybe going back to school and doing something in accounting because I feel that an accountant is needed anywhere for non-profit, for profit." (INT8)

One participant worried about changing careers in the midst of the pandemic and prioritized feeling secure in herself and her job over making a major decision during an unpredictable time.

"I'm not saying no, that I wouldn't change my field. But again, like I want to feel secure in myself before I go and make decisions, because we're not making decisions all willy nilly anymore." (INT14)

\subsubsection{Financial Changes Brought on by the Pandemic Impacted Educational Plans}

Some participants mentioned that a change in their financial situation caused by the pandemic affected their educational plans.

"I do plan on signing back up for courses. I just financially need to find that that money, as COVID did affect 
that a little bit because of, you know, there was some extra costs and things like that. So that's put on pause for now." (INT3)

Three participants stated they had been laid off, with one of them stating that losing her job delayed her plan to return to school in the fall.

"So right before the coronavirus came and we all had to go into quarantine, I had went to Laurentian because I know I owe them money. So I owed them like fourteen hundred dollars for classes that I failed, maybe? I don't remember why I owe the money, I just know I owe the money. And I had, I had gotten the number and I had just gotten my tax return, so I had gotten like a really big tax return that I wasn't expecting. And so I figured, okay, well, I have all this money now. I should go pay Laurentian and I can register for September and I could go back to school this fall. So I waited and then Laurentian closed down and then I lost my job, and while I was waiting for, like the CERB [Canada Emergency Response Benefit] to come or like the EI to come, I ended up having to dip into the money that I was going to pay Laurentian with. And it just crushed my dreams and now I have to wait again." (INT6)

Conversely, one of the other two participants mentioned that government payments actually enabled him to go back to school.

"Because of that, they're gonna be paying me like a living allowance. Because I was laid off so capable of going to school now not having to worry about, you know, the bills as much as still I can still get a part-time job after the schooling stuff. But it still helps me a lot. They're paying my tuition because of this, which helps a lot because I didn't want to go back in debt and not working while having two kids at home. So it kind of helped me out in the long run with this virus." (INT10)

\subsection{Optimism and Hope Despite Challenges Posed by the pandemic}

Overall, the interviews had a largely positive undertone, with the majority of participants (75\%) highlighting the unexpected benefits of the pandemic and hope for the future.

\subsubsection{Participants Made the Most of the Pandemic by Focusing on the Positives}

Despite the difficulties and misfortunes that the pandemic caused, most participants focused on the good that the pandemic brought into their lives. Although they acknowledged the challenges that resulted from the pandemic, participants found ways to persevere and make the best of the situation. One participant said,

"The pandemic has been annoying to some [but] I've used this time to really kind of like, dig deep and, you know, bring to light some things that I've been hiding for a while. So I have more motivation now. And an understanding, an idea of what it is that I need to do and what my purpose is." (INT14)

The same participant said,

"Coronavirus was like a huge fork in the road. But I still managed to accomplish a lot of my goals that I wanted to even though they didn't follow up, they didn't follow through." (INT14)

Other participants felt that their career paths benefited from the pandemic, stating

"The virus actually helped me in my career." (INT3)

One participant who was pursuing a career in e-sports attributed increased job opportunities to the pandemic.

"The pandemic for anything that I want to do absolutely helps...there's so many jobs that branch off from just actually streaming, there's so many things you could do and that's literally because of COVID." (INT4)

\subsubsection{Hope for Achieving Pre-Pandemic Educational and Occupational Plans Remains}

Participants were generally hopeful about achieving their educational and occupational aspirations, although they tended to speak with cautious optimism. They realized that the pandemic caused many changes within education, work, and their personal lives but felt that it did little to change their aspirations. Participants said,

"I feel hopeful that it's definitely attainable. So I don't feel like the virus has had an impact in what I hope for myself personally and academically" (INT7)

"I feel quite hopeful that my future is still going to be okay." (INT13)

"I'm still quite hopeful. I'm a firm believer if it was meant to happen, it's going to happen, so we're totally fine." (INT15)

"I think it's changed my plans, but not completely, just my approach to, how to, how to pursue them." (INT9) Another participant remained not only hopeful in her own ability to achieve their educational goals but also in 
schools' ability to adapt. She stated,

"If coronavirus doesn't get any better, I think that they will still make arrangements for us to go into college and be able to pursue our education and finish what we need to finish in order to graduate." (INT14)

\section{Discussion}

In this small sample of participants, educational paths and aspirations largely remain unchanged by the COVID-19 pandemic. Findings indicate that although the pandemic changed the timeline of many participants' paths, many found that the pandemic actually made future educational plans more accessible, as expanded virtual learning options will make it easier for them to attend school. Many participants seemed hopeful that the increase in remote learning opportunities would remain even after the pandemic subsides. Through this form of learning, they feel they will be better able to balance work and family responsibilities than if they are required to attend classes in person. The ability to work while taking classes will also help with affording higher education.

Most young adults in our study expressed concern about the quality and effectiveness of distance learning compared with in-person learning. This attitude appears to be shared with many post-secondary students and faculty in Canada and beyond. For example, a poll conducted by the Ontario Confederation of University Faculty Associations (2020) reported that $62 \%$ of students and $76 \%$ of faculty feel that online learning during the pandemic has negatively impacted the quality of university education in Ontario. Similarly, a study in India reported that $69.5 \%$ of surveyed students felt that better learning takes place in physical classrooms than online (Chakraborty et al., 2020). Some reporting suggests that remote learning may be beneficial for some students who experienced social pressures or distractions in classroom settings (e.g., Gilman, 2020; Harris, 2020). However, most students find distance learning to be of lower quality due to increased distractions at home, difficulty in self-regulating learning, and a lack of direct interaction with instructors and peers (Kalman et al., 2020). Technological difficulties such as a poor Internet connection can also make it challenging for students to engage in class fully. Considering the importance of students' engagement with a school to their aspirations (Gutman \& Schoon, 2018), decreased engagement as a result of distance learning during COVID-19 may lead to lowered aspirations, especially if distance learning remains prevalent after the pandemic ends. Conversely, working remotely was viewed favourably by participants and has been similarly well-received by many working individuals in Canada and around the world (Aczel et al., 2021; Ipsen et al., 2021; Leger \& Association for Canadian Studies, 2021), although the proportion of jobs that can be performed from home is higher in wealthier countries, and the feasibility of working from home may vary for workers based on housing and family considerations. Nevertheless, in this study, participants who were able to work from home listed zero commute time and the ability to care for their children during work hours as major benefits.

The pandemic prompted some participants to consider returning to school. This trend is commonly seen during economic downturns, as several people believe that the benefits of returning to school during periods of recession or high unemployment outweigh the costs (Barr \& Turner, 2013). Moreover, as one participant mentioned, the feeling of job insecurity may persuade some people to pursue an educational path that leads to a more stable career. This desire for greater job security is reflected in the disproportionate increase in applications to graduate and professional school programs across North America (Law School Admission Council, 2021; Weiner, 2020).

However, some young adults in this study were not able to return to school despite a desire to further their education. The pandemic put a financial strain on multiple participants, which affected their ability to pay for school. Cost remains a major barrier to higher education, and the economic impact of the pandemic has exacerbated this issue for many people hoping to return to school. Although educational aspirations remain high, it remains to be seen if financial barriers brought on by the pandemic will lower educational expectations. Discrepancies between educational aspirations - the level of education hoped to achieve - and educational expectations - the level of education they think will be achieved - have been associated with emotional and behavioural problems, as well as test anxiety (Boxer et al., 2011); further research is required to determine the effect that the pandemic will have on such discrepancies.

The young adults living in Ontario who shared their stories generally expressed an optimistic view of the pandemic, focusing on the benefits rather than the drawbacks of staying at home and working or learning virtually. The pandemic seemed to give them time to reflect on priorities and future plans. For the majority of participants, the pandemic did not dampen their hopes, dreams, and determination to continue pursuing their goals. Most explicitly stated that they felt hopeful about accomplishing educational and occupational goals, although this perspective was expressed only 5-7 months into the pandemic and thus could have changed as the pandemic progressed. This is especially true given the negative impact this pandemic has had on mental health (Xiong et al., 2020) and the association between psychological distress and educational aspirations (Rothon et al., 2011). 
This study has some limitations. First, we captured only a brief snapshot of the impact of COVID-19 on young adults' educational and occupational aspirations, and these may have evolved as the pandemic progressed. Second, interviews were only conducted through Zoom, and this may have narrowed the potential pool of participants to those who had access to and familiarity with this format. At least one interested participant was unable to participate because he did not have access to a strong Internet connection or reliable phone service. Unfortunately, our resources in conjunction with the pandemic prevented our research team from being able to offer in-person interviews. Relatedly, there may be unique differences between our participants and individuals who were invited but chose not to respond to our invitation for an interview. Finally, our sample was relatively small $(N=16)$ and limited to 29 -year-olds who grew up in Ontario, and the sample was approximately $62 \%$ women. As such, findings may not be representative of the broader adult population. Generalizations may be made to adults similar in age who grew up in Ontario, Canada, because of the diversity in our sample on educational level, partnership status, living situation, and part-time and full-time employment.

\section{Conclusion}

The COVID-19 pandemic has created unprecedented changes in how we work and learn. Despite the impact of this pandemic on the timeline of young adults' educational plans and the type of learning in which they may engage (i.e., virtual versus in-person), these constraints have not drastically affected their educational aspirations. Many continue to regard the future with optimism and see opportunities for continued learning and growth. The shift to more virtual learning and working has benefited many by allowing greater access to educational opportunities and greater flexibility in their schedules. Some challenges with distance learning remain, and changes in financial situation or feelings of job insecurity may have disrupted the plans of some participants. Nevertheless, for many young adults, hope for the future remains bright.

\section{Acknowledgements}

We want to thank all the individuals who were interviewed for this study, as well as Ashleigh Kong, for her contributions to our initial literature review. Furthermore, this manuscript draws on research supported in part by the Social Sciences and Humanities Research Council.

\section{References}

Aczel, B., Kovacs, M., van der Lippe, T., \& Szaszi, B. (2021). Researchers working from home: Benefits and challenges. PLOS One, 16(3), e0249127. https://doi.org/10.1371/journal.pone.0249127

Agger, C., Meece, J., \& Byun, S. Y. (2018). The influences of family and place on rural adolescents' educational aspirations and post-secondary enrollment. Journal of Youth and Adolescence, 47, 2554-2568. https://doi.org/10.1007/s10964-018-0893-7

Ahuja, A. (2016). A Study of Self-Efficacy among Secondary School Students in relation to Educational Aspiration and Academic Achievement. Educational Quest, 7(3), 275-283. https://doi.org/10.5958/2230-7311.2016.00048.9

Barr, A., \& Turner, S. E. (2013). Expanding enrollments and contracting state budgets: The effect of the Great Recession on higher education. Annals of the American Academy of Political \& Social Science, 650(1), 168-193. https://doi.org/10.1177/0002716213500035

Boxer, P., Goldstein, S. E., DeLorenzo, T., Savoy, S., \& Mercado, I. (2011). Educational aspiration-expectation discrepancies: Relation to socioeconomic and academic risk-related factors. Journal of Adolescence, 34(4), 609-617. https://doi.org/10.1016/j.adolescence.2010.10.002

Chakraborty, P., Mittal, P., Gupta, M. S., Yadav, S., \& Arora, A. (2020). Opinion of students on online education during the COVID-19 pandemic. Human Behavior and Emerging Technologies, 1-9. https://doi.org/10.1002/hbe2.240

Duta, A., Wielgoszewska, B., \& Iannelli, C. (2021). Different degrees of career success: Social origin and graduates' education and labour market trajectories. Advances in Life Course Research, 47, 100376. https://doi.org/10.1016/j.alcr.2020.100376

Frostick, C., Phillips, G., Renton, A., \& Moore, D. (2016). The educational and employment aspirations of adolescents from areas of high deprivation in London. Journal of Youth and Adolescence, 45, 1126-1140. https://doi.org/10.1007/s10964-015-0347-4

García-Morales, V. J., Garrido-Moreno, A., \& Martín-Rojas, R. (2021). The transformation of higher education after the COVID disruption: Emerging challenges in an online learning scenario. Frontiers in Psychology, 12, 616059. https://doi.org/10.3389/fpsyg.2021.616059 
Geckova, M., Tavel, P., van Dijk, J. P., Abel, T., \& Reijneveld, S. A. (2010). Factors associated with educational aspirations among adolescents: cues to counteract socioeconomic differences? BMC Public Health, 10, 154. https://doi.org/10.1186/1471-2458-10-154

Gilman, A. (2020, October 3). Remote learning has been a disaster for many students. But some kids have thrived. The Washington Post. Retrieved from https://www.washingtonpost.com/local/education/remote-learning-has-been-a-disaster-for-many-students-b ut-some-kids-have-thrived/2020/10/02/5e7f3434-0400-11eb-a2db-417cddf4816a_story.html

Gutman, L. M., \& Schoon, I. (2018). Emotional engagement, educational aspirations, and their association during secondary school. Journal of Adolescence, 67, 109-119. https://doi.org/10.1016/j.adolescence.2018.05.014

Harris, E. A. (2020, May 20). Not everyone hates remote learning. For these students, it's a blessing. The New York Times. Retrieved from https://www.nytimes.com/2020/05/20/nyregion/coronavirus-students-schools.html

Kalman, R., Esparza, M. M., \& Weston, C. (2020). Student views of the online learning process during the COVID-19 pandemic: A comparison of upper-level and entry-level undergraduate perspectives. Journal of Chemical Education, 97, 3353-3357. https://doi.org/10.1021/acs.jchemed.0c00712

Labour Market Information Directorate. (2020). Ontario labour market bulletin: April 2020. Retrieved from http://www.edsc-esdc.gc.ca/img/edsc-esdc/jobbank/LMBs/202004/ON/202004OntarioLabourMarketBulleti nE.pdf

Law School Admission Council. (2021). Current volume summary. Retrieved from https://report.lsac.org/VolumeSummaryOriginalFormat.aspx?Format=PDF

Leger, \& Association for Canadian Studies. (2020). Leger's weekly survey (September 28, 2020). Retrieved from https://2g2ckk18vixp3neolz4b6605-wpengine.netdna-ssl.com/wp-content/uploads/2020/09/Legers-WeeklySurvey-September-28th-2020-min.pdf

Neal, G., \& Yelland, N. (2014). (Dis)advantage and (dis)engaged: Reflections from the first year of secondary school in Australia. Journal of Education and Learning, 3(3), 1-14. https://doi.org/10.5539/jel.v3n3p1

Ontario Confederation of University Faculty Associations. (2020). OCUFA 2020 study: COVID-19 and the impact on university life and education. Retrieved from https://ocufa.on.ca/assets/OCUFA-2020-Faculty-Student-Survey-opt.pdf

Puzić, S., Odak, I., \& Šabić, J. (2019). Educational outcomes and aspirations of upper secondary school students: The cultural capital and relative risk aversion perspectives. Sociologija, 61(3), 368-388. https://doi.org/10.2298/SOC1903368P

Rothon, C., Arephin, M., Klineberg, E., Cattell, V., \& Stansfeld, S. (2011). Structural and socio-psychological influences on adolescents' educational aspirations and subsequent academic achievement. Social Psychology of Education, 14(2), 209-231. https://doi.org/10.1007/s11218-010-9140-0

Scandone, B. (2018). Re-thinking aspirations through habitus and capital: The experiences of British-born Bangladeshi women in higher education. Ethnicities, 18(4), 518-540. https://doi.org/10.1177/1468796818777541

Shakya, Y. B., Guruge, S., Hynie, M., Akbari, A., Malik, M., Htoo, S., ... Alley, S. (2010). Aspirations for higher education among newcomer refugee youth in Toronto: Expectations, Challenges, and Strategies. Refuge: Canada's Journal on Refugees, 27(2), 65-78. https://doi.org/10.25071/1920-7336.34723

Statistics Canada. (2020). Postsecondary enrolments, by field of study, International Standard Classification of Education, age group and gender. Table 37-10-0112-01. https://doi.org/10.25318/3710011201-eng

Stockfelt, S. (2016). Economic, social and embodied cultural capitals as shapers and predictors of boys' educational aspirations. The Journal of Educational Research, 109(4), 351-359. https://doi.org/10.1080/00220671.2014.968911

Wang, M. T. \& Eccles, J. S. (2012). Adolescent behavioral, emotional, and cognitive engagement trajectories in school and their differential relations to educational success. Journal of Research on Adolescence, 22(1), 31-39. https://doi.org/10.1111/j.1532-7795.2011.00753.x

Weiner, S. (2020, October 22). Applications to medical school are at an all-time high. What does this mean for applicants and schools? Association of American Medical Colleges. Retrieved from https://www.aamc.org/news-insights/applications-medical-school-are-all-time-high-what-does-mean-applic ants-and-schools 
Williams, G. C., Battista, K., \& Leatherdale, S. T. (2020). An examination of how age of onset for alcohol, cannabis, and tobacco are associated with school outcomes in grade 12. Addictive Behaviors, 102, 106215. https://doi.org/10.1016/j.addbeh.2019.106215

Xiong, J., Lipsitz, O., Nasri, F., Lui, L. M. W., Gill, H., Phan, L., .. McIntyre, R. S. (2020). Impact of COVID-19 pandemic on mental health in the general population: A systematic review. Journal of Affective Disorders, 277, 55-64. https://doi.org/10.1016/j.jad.2020.08.001

\section{Copyrights}

Copyright for this article is retained by the author, with first publication rights granted to the journal.

This is an open-access article distributed under the terms and conditions of the Creative Commons Attribution license (http://creativecommons.org/licenses/by/4.0/). 